\title{
TRANSFERABLE FLUOROQUINOLONE RESISTANCE IN ENTEROBACTERIACEAE AND PSEUDOMONAS AERUGINOSA ISOLATED FROM HEMOCULTURES SHORT COMMUNICATION
}

\author{
Nad’a Kulková1, ${ }^{1,}$, Marta Babálová2, ${ }^{2}$, Jaroslava Brňová1, ${ }^{1,}$, Vladimír Krčméry1,3 \\ 'Department of Laboratory Medicine, Faculty of Health Care and Social Work, Trnava University in Trnava, Trnava, Slovakia \\ ${ }^{2}$ Department of Chemotherapy, Faculty of Medicine, Slovak Medical University, Bratislava, Slovakia \\ ${ }^{3}$ Laboratory of Molecular Microbiology, St. Elisabeth University of Health and Social Sciences, Bratislava, Slovakia
}

\section{SUMMARY}

Background: The main mechanisms causing high-level resistance to fluoroquinolones ( $F Q)$ are encoded chromosomally; that includes mutations in genes coding DNA-gyrase, but overexpression of efflux pumps contributes to increased minimum inhibitory concentration (MIC) of FQ as well. However, genes responsible for FQ-resistance may be harboured in transferable/conjugative plasmids. For some time, there was an assumption that resistance to $F Q$ cannot be transferable in conjugation due to their synthetic origin, until 1998, when plasmid-mediated resistance transmission in Klebsiella pneumoniae was proved. We aimed to detect the occurrence of transferable FQ-resistance among Gram-negative bacteria isolated from patients in Czech and Slovak hospitals.

Methods: In this study, we tested 236 clinical isolates of Gram-negative bacteria for transferable resistance. Among relevant isolates we performed PCR detection of transferable fluoroquinolone genes (qnr).

Results: We have observed transfer of determinants of cephalosporin-resistance, aminoglycoside resistance as well as FQ-resistance (in 10 cases; $4.24 \%$ ) not only intra-species but inter-species too. The presence of qnr gene was detected in two isolates of forty tested (5\%). We have also observed that determinants of cephalosporin-resistance and aminoglycoside-resistance were linked to those of FQ-resistance and were transferred en block in conjugation.

Conclusion: We have proved that resistance to fluoroquinolones can be transferred horizontally via conjugation among Gram-negative bacteria of different species and is associated with resistance to other antibiotics.

Key words: fluoroquinolones, resistance, transferable-fluoroquinolone resistance, conjugation, Gram-negative bacteria

Address for correspondence: N. Kulková, Department of Laboratory Medicine, Faculty of Health Care and Social Work, Trnava University in Trnava, Univerzitné námestie 1, 91843 Trnava, Slovakia. E-mail:kulkova.nada@gmail.com

\section{INTRODUCTION}

As FQ are antibiotics of synthetic origin, it was predicted that resistance to this group would not evolve and would not be transmissible. Soon it was demonstrated that this assumption was incorrect and in 1997-1998 horizontally transferred resistance to FQ was proved by Gómez-Gómez et al. (1997) and Martínez-Martínez et al. (1998) (1, 2). Since that time, numerous reports of plasmid-mediated FQ-resistance acquisition in different bacterial species were published (3-6). Generally, plasmid-mediated FQ resistance confers only to low-level resistance, as the main chromosomally encoded mechanism - modification of DNA gyrase - is the reason for high-level resistance. Transferable determinants of FQ resistance are represented by $q n r$ genes (coding Qnr proteins), $a a c\left(6^{\prime}\right)-I b-c r$, qepA and $о q \times A B$.

Qnr proteins, belonging to pentapeptide-repetitive proteins group, were the firstly discovered transferable elements causing FQ-resistance (2). As yet, five different $q n r$ genes were discovered in Enterobacteriaceae, those being plasmid-located $(3,7)$ and also QnrVC-like protein was revealed in Vibrio cholerae, which is not located on plasmid (8).

Discovery of FQ-resistance mediated by aac(6')-Ib-cr enzyme was rather surprising, seeing that normally aac ( $\left.6^{\prime}\right)$ is responsible for resistance to aminoglycosides (9). The gene $a a c\left(6^{\prime}\right)-I b-c r$ is only slightly different from $a a c\left(6^{\prime}\right)-I b$ (2 mutations) and it has acquired ability of ciprofloxacin acetylation. It should be mentioned, that $a a c\left(6^{\prime}\right)-I b-c r$ contributes only to small increase in MIC levels (5).

Another transferable resistance mechanism is active efflux carried out by efflux pumps QepA and OqxAB (10). QepA pump has a significant structural similarity to transmembrane subunits of MFS (major facilitator superfamily) pumps and it leads to decreased susceptibility to hydrophillic FQ. OqxAB, consisting of two genes oqxA and oqxB, is localised in one operon. OqxAB belongs to RND (resistance nodulation division) group of pumps and it causes resistance not only to $\mathrm{FQ}$, but also to other agents $(10,11)$.

The aim of this study was to assess the occurrence of transferable FQ-resistance among Gram-negative bacteria isolated in Slovakia and the Czech Republic. 


\section{MATERIAL AND METHODS}

\section{Microorganisms}

In our study, multiresistant clinical isolates of Gram-negative bacteria isolated from blood of septic patients with positive hemoculture sampled from hospitals in Bratislava, Slovakia, during the period of 2 months (November 2011 - December 2011) were included as well as isolates from the Regional Hospital in Př́bram, Czech Republic, collected during the period of 3 years (January 2009 - December 2011). One hundred and ninety-six Czech and forty Slovak samples, respectively, were obtained and included for transfer screening.

\section{Susceptibility Testing}

Antibiotic susceptibility to ampicillin, piperacillin, cefuroxime, cefoperazone, ceftazidime, aztreonam, gentamicin, amikacin, tetracycline, trimethoprim/sulfamethoxazole, ampicillin/ sulbactam, piperacillin/tazobactam, cefotaxime, cefoperazone/ sulbactam, cefepime, meropenem, tobramycine, ciprofloxacin, colimycine, and tigecycline was determined using disc diffusion method according to the European Committee on Antimicrobial Susceptibility Testing (EUCAST) guidelines $(12,13)$.

\section{Transferability/Conjugation Testing}

Transferability of resistance-determinants was assessed by conjugation by phenotypic method. Strains of rifampin-resistant Escherichia coli 3110, rifampin-resistant Proteus mirabilis P38, rifampin-resistant Pseudomonas aeruginosa 1008, and rifampinresistant $P$. aeruginosa 1670 were used as recipient strains. E. coli strain ATCC 25922 was used as a control strain. Donor strains were incubated overnight in Nutrient broth no. 2 (Biolife Italiana) at $37^{\circ} \mathrm{C}$ to reach logarithmic phase. After incubation, $1 \mathrm{ml}$ of donor culture was mixed with $1 \mathrm{ml}$ of competent recipient strain culture and cultivated for 20 hours at $37^{\circ} \mathrm{C}$. Commixture of donors and recipients was then put on bi-antibiotic plates containing selective antibiotic (rifampin) and one of the following antibiotics: cefotaxime, ceftazidime, cefepime, cefoperazone, meropenem, and ofloxacin $(5 \mu \mathrm{g} /$ $\mathrm{mL}$ ), which were monitored for transferability of their resistance determinants. After 20 hours of cultivation at $37^{\circ} \mathrm{C}$, positivity or negativity of transfer was assessed. Control experiments, with recipient strains and donor strains cultivated alone under the same condition as mixed cultures, were run in parallel to exclude recombinants selection by mutation. Transconjugants, which were proved to acquire at least one resistance determinant, were then analyzed to asses which genes are in connection, with following protocol. Single isolated colony of transconjugants was incubated in Nutrient broth no. 2 (Biolife, Italy) overnight at $37^{\circ} \mathrm{C}$ and then applied on antibiotic plates according to their original resistance profile. After incubation, positive results were evaluated as a growth on the row of antibiotic plates indicating which resistance determinants are linked to each other and transferred during conjugation together.

\section{Detection of qnr Genes}

In isolates proved to be able to transfer resistance determinants we performed simplex PCR to detect presence of $q n r$ gene as previously described by Jacoby and colleagues (14). DNA was isolated using spin-column Bacterial DNA Extraction Kit (Ecoli, Bratislava, Slovakia) according to manufacturer's instructions (15). Isolated DNA ( $2 \mu 1)$ was used as a template in PCR reaction $(50 \mu \mathrm{l})$. Master mix (Solis BioDyne, Tartu, Estonia) consisted of $10 \mathrm{X}$ buffer BD (0.8 M Tris-HCl, $0.2 \mathrm{M}$ $\left(\mathrm{NH}_{4}\right)_{2} \mathrm{SO}_{4}$ ), $25 \mathrm{mM} \mathrm{MgCl}_{2}$ (to final concentration of $2.5 \mathrm{mM}$ ), $20 \mathrm{mM}$ deoxyribonucelotide triphosphates mix (dNTPs to final concentration of $200 \mu \mathrm{M}$ ), forward and reverse primers $(0.3 \mu \mathrm{M}$ of each), DNA polymerase $(5 \mathrm{U})$, and ultrapure water for PCR. We used oligonucleotide primers to amplify the $q n r$ gene as following: forward 5'-GATAAAGTTTTTCAGCAAGAGG; and reverse 5'-ATCCAGATCGGCAAAGGTTA. Reaction was run in thermal cycler under the following conditions: initial denaturation for $10 \mathrm{~min}$ at $95^{\circ} \mathrm{C}$, then 35 cycles of amplification consisting of $1 \mathrm{~min}$ at $95^{\circ} \mathrm{C}, 1 \mathrm{~min}$ at $54^{\circ} \mathrm{C}$ and $1 \mathrm{~min}$ at $72^{\circ} \mathrm{C}$; and $10 \mathrm{~min}$ at $72^{\circ} \mathrm{C}$ for the final extension.

Products were subjected to gel electrophoresis in $2 \%$ agarose gel (Serva, Heidelberg, Germany), stained with UltraPower (Bio-Teke, Beijing, China) and the presence of 593 bp product was considered as positive.

\section{RESULTS}

Out of 236 clinical isolates obtained, 10 (4.24\%) belonging to species E. coli, P. mirabilis, Ps. aeruginosa, K. pneumoniae, and Providencia stuartii were noticed to be able to transfer their FQ-resistance determinants. During the previous months, we have noticed slowly increasing prevalence of FQ-resistance transferability among clinical isolates (1 case in 2009, 2 cases in 2010, 3 cases in 2011), which altogether made up for occurrence of 6 cases among 196 isolates tested (3.06\%) until November 2011. In the last two months of the year 2011 (November - December), the occurrence increased to $10 \%$ (4 positives among 40 tested). Details of transfer, genetic analysis and characteristics of transfer-positive strains isolated in 2011 are summarized in Table 1.

Ciprofloxacin minimum inhibitory concentration (MIC) in the transfer-positive isolates ranged from $1 \mathrm{mg} / \mathrm{l}$ to $>4 \mathrm{mg} / \mathrm{l}$.

Among 40 isolates collected during the last two months of 2011, we detected the qnr gene to be present in two of them (5\%).

Resistance to first-generation quinolones (nalidixic acid) was recorded in 140 isolates of 194 tested (72.16\%; please note, that Pseudomonadaceae were not tested), and high-level resistance (thus to second-generation quinolones, ofloxacin and ciprofloxacin) was recorded in 121 isolates (51.27\%).

Ceftazidime and cefepime resistances were the most frequently transferred resistotypes. After the genetic analysis, we found out that ofloxacin-resistance determinants were linked to determinants of cefotaxime, ceftazidime, cefepime, and cefoperazone resistance in 4 isolates, but also association with kanamycin and ticarcillin-resistance determinants was observed. Noteworthy, donor strains were able to transfer their determinants not only to recipients of the same genus, but also inter-species as follows: P. mirabilis to E. coli and vice versa; and Ps. aeruginosa to P. mirabilis. 
Table 1. Transfer patterns of tested isolates

\begin{tabular}{|c|c|c|c|c|}
\hline $\begin{array}{l}\text { Isolate characteristics } \\
\text { (species/internal number/ } \\
\text { origin) }\end{array}$ & Ciprofloxacin MIC & Recipient strain & $\begin{array}{l}\text { Primary transferable } \\
\text { resistance }\end{array}$ & $\begin{array}{l}\text { Gene linkage analysis - } \\
\text { cotransfer }\end{array}$ \\
\hline E. coli/28/hemoculture & $>4$ mg/l & P. mirabilis P38 & Cefotaxim & $\begin{array}{l}\text { Cefotaxime + cetazidime }+ \\
\text { cefoperazone }+ \text { cefepime }+ \\
\text { ofloxacin }\end{array}$ \\
\hline E. coli/29/hemoculture & $>4$ mg/l & P. mirabilis P38 & Cefoperazone & $\begin{array}{l}\text { Cefotaxime + cetazidime }+ \\
\text { cefoperazone }+ \text { cefepime }+ \\
\text { ofloxacin }\end{array}$ \\
\hline \multirow[t]{2}{*}{ E. cloacae/30/hemoculture } & \multirow[t]{2}{*}{$1 \mathrm{mg} / \mathrm{l}$} & E. coli 3110 & Ceftazidime & $\begin{array}{l}\text { Cefotaxime + ceftazidime + } \\
\text { cefoperazone }\end{array}$ \\
\hline & & P. mirabilis P38 & Ceftazidime + cefoperazone & $\begin{array}{l}\text { Cefotaxime + ceftazidime + } \\
\text { cefoperazone }\end{array}$ \\
\hline \multirow[t]{2}{*}{ P. mirabilis/33/hemoculture } & \multirow[t]{2}{*}{$4 \mathrm{mg} / \mathrm{l}$} & E. coli 3110 & Ceftazidime & Ceftazidime + cefoperazone \\
\hline & & P. mirabilis P38 & Cefoperazone & $\begin{array}{l}\text { Cefotaxime + cetazidime }+ \\
\text { cefoperazone }+ \text { cefepime }+ \\
\text { ofloxacin }\end{array}$ \\
\hline $\begin{array}{l}\text { Ps. aeruginosa/36/hemoc- } \\
\text { ulture }\end{array}$ & $>4$ mg/l & P. mirabilis P38 & Cefepime & $\begin{array}{l}\text { Cefotaxime }+ \text { cetazidime }+ \\
\text { cefoperazone }+ \text { cefepime }+ \\
\text { ofloxacin }\end{array}$ \\
\hline
\end{tabular}

MIC - minimum inhibitory concentration

Table 2. Resistance of E. coli to FQ in selected countries of Central Europe (Czech Republic, Austria, Slovakia, Hungary, and Poland). Comparison of ten years data from 2002 and 2011 retrieved from EARS-Net Database

\begin{tabular}{|c|c|c|c|c|c|c|}
\hline & \multicolumn{3}{|c|}{2002} & \multicolumn{3}{|c|}{2011} \\
\hline & Number of isolates & $\mathbf{R}$ & $\%$ & Number of isolates & $\mathbf{R}$ & $\%$ \\
\hline Austria & 472 & 48 & 10.17 & 3,162 & 704 & 22.26 \\
\hline Czech Republic & 1,586 & 165 & 10.40 & 2,682 & 630 & 23.49 \\
\hline Hungary & 328 & 34 & 10.37 & 1,213 & 378 & 31.16 \\
\hline Poland & 133 & 14 & 10.53 & 1,141 & 312 & 27.34 \\
\hline Slovakia & 214 & 31 & 14.49 & 737 & 309 & 41.3 \\
\hline Total & 2,33 & 292 & 10.8 & 8,35 & 2.33 & 26.1 \\
\hline
\end{tabular}

$\mathrm{R}$ - resistant isolates

\section{DISCUSSION}

Transferable plasmid-mediated FQ-resistance is an issue of public health concern, whereas such mechanism was long waived as unlikely. Since discovery of plasmid mediated FQ-resistance several studies have been published on this topic. The level of resistance of Enterobacteria and $P$. aeruginosa to FQ is alarming and significantly increasing in Europe including the Central European Region (Table 2). Increase from $10.68 \%$ to $26.11 \%$ was noticed among E. coli by the European Centre for Disease Prevention and Control (ECDC) in that area (16). Considerably high FQ resistance among E. coli, K. pneumoniae and Ps. aeruginosa is reported by ECDC in Slovakia (data from 2011), reaching 41.9\%, 70.6\% and $58.7 \%$, respectively (17). We can assume that such a high rate of FQ resistance may be associated with their frequent use in clinical practice, as Slovakia belongs to the 'top 10' European countries with the highest outpatient use of quinolones (17).

The presented experiments have showed that ofloxacineresistance can be horizontally transferred during conjugation in Gram-negative bacteria, which is in contrast to previous findings of Kim et al., who did not proved either direct transfer or cotrans- fer. Therefore, they suggested location of oqxAB on nonconjugative plasmid of E. cloaceae and K. pneumoniae (18). We found transfer of ofloxacin resistance determinant during conjugation in 10 isolates, thus plasmid-typing would be advisable.

To our best knowledge, this is the first study to monitor the occurrence of qnr genes in Slovak clinical samples. We detected the $q n r$ gene in 2 isolates (5\%), which indicates that it is not extremely frequent. Thus, other transferable and chromosomally encoded mechanisms are probably contributing to the phenotype of FQ-resistance. Similar results were found in other European countries, e.g. in Poland where the prevalence of qnr was 8.3\% (19) or in Italy where the prevalence was 5.02\% (20). However, our study is biased by relative small range; therefore we suppose further studies to be performed on this issue.

Another finding revealed by our experiments was the fact of inter-species transferability of FQ-resistance determinants. $P$. mirabilis donor was able to transfer FQ resistance not only to recipient strains of $P$. mirabilis but also to recipients $E$. coli, and vice-versa (E. coli donors to $P$. mirabilis recipients), which was similar in Ps. aeruginosa transferring its determinants to Proteus sp. 
We also found ofloxacin-resistance determinants being closely linked with those of cephalosporin-resistance and with aminoglycoside-resistance, probably located on the same plasmid, suggesting association between those types of resistances. That is in agreement with findings of Sahm et al., who revealed association of FQ and ceftazidime resistance in Enterobacteriaceae and Ps. aeruginosa (21).

Briales et al. found that qnr and aac(6')-Ib-cr genes, responsible for FQ resistance, were located on plasmid and transferable as well as their association with ESBL production (22). Such results are consistent with our ones presented above. Interestingly, as the others $(22,23)$, we have also noticed an increase of occurrence of transferable FQ-resistance compared to the previous period (January 2009 - November 2011) from 3.06\% prevalence to $10 \%$ in the last 2 months of 2011.

\section{CONCLUSIONS}

We have showed that resistance to fluoroquinolones can be transferred horizontally via conjugation among Gram-negative bacteria of different species and is associated with resistance to different antibiotic classes - cephalosporins and aminoglycosides. Increasing FQ-resistance is a public health problem considering their wide use on one side, and spreading resistance by plasmids on the other. This emphasizes the need of surveillance of FQresistance which should be accompanied by analysis of its transferability and its possible association with other resistance patterns should be kept in investigators' mind. Informing clinicians and keeping them up-to-date about the potential risk of excessive FQ use in practice is of great importance, too.

\section{Acknowledgement}

Authors wish to thank to all contributing institutions and laboratories, namely to HPL Servis spol. s r.o. in Bratislava, AnalytX, s.r.o. in Trnava, to Dr. Petr Ježek from Př́ibram Hospital, and to professor Anna Lišková from Nitra University Hospital, Department of Clinical Microbiology, for cooperation during collection of relevant isolates. Particularly, we would like to thank to professor Lišková for providing us valuable advices as well as standard strain.

This work was supported by Trnava University Academic Grant, Number 7/TU/12, part of 2012 Development Fund assignments D 1.1.1. - D 1.1.3 and D 1.2.2. - D 1.2.7.

\section{Conflict of Interests}

None declared

\section{REFERENCES}

1. Gómez-Gómez JM, Blázquez J, Espinosa De Los Monteros LE, Baquero MR, Baquero F, Martínez JL. In vitro plasmid-encoded resistance to quinolones. FEMS Microbiol Lett. 1997 Sep 15;154(2):271-6.

2. Martínez-Martínez L, Pascual A, Jacoby GA. Quinolone resistance from a transferable plasmid. Lancet. 1998 Mar 14;351(9105):797-9.

3. Wang A, Yang Y, Lu Q, Wang Y, Chen Y, Deng L, et al. Presence of qnr gene in Escherichia coli and Klebsiella pneumoniae resistant to ciprofloxacin isolated from pediatric patients in China. BMC Infect Dis. 2008 May 22;8:68

4. Longhi C, Conte MP, Marazzato M, Iebba V, Totino V, Santangelo F, et al. Plasmid-mediated fluoroquinolone resistance determinants in Escherichia coli from community uncomplicated urinary tract infection in an area of high prevalence of quinolone resistance. Eur J Clin Microbiol Infect Dis. 2012 Aug;31(8):1917-21.

5. Poirel L, Cattoir V, Nordmann P. Plasmid-mediated quinolone resistance; interactions between human, animal, and environmental ecologies. Front Microbiol. 2012 Feb 2;3:24

6. Chowdhury G, Pazhani GP, Nair GB, Ghosh A, Ramamurthy T. Transferable plasmid-mediated quinolone resistance in association with extended-spectrum $\beta$-lactamases and fluoroquinolone-acetylating aminoglycoside-6'-N-acetyltransferase in clinical isolates of Vibrio fluvialis. Int J Antimicrob Agents. 2011 Aug;38(2):169-73.

7. Jacoby GA. Mechanisms of resistance to quinolones. Clin Infect Dis. 2005 Jul 15;41 Suppl 2:S120-6.

8. Fonseca EL, Dos Santos Freitas F, Vieira VV, Vicente ACP. New qnr gene cassettes associated with superintegron repeats in Vibrio cholerae O1. Emerg Infect Dis. 2008 Jul;14(7):1129-31.

9. Robicsek A, Strahilevitz J, Jacoby GA, Macielag M, Abbanat D, Park CH, et al. Fluoroquinolone-modifying enzyme: a new adaptation of a common aminoglycoside acetyltransferase. Nat Med. 2006 Jan;12(1):83-8.

10. Yamane K, Wachino JI, Suzuki S, Kimura K, Shibata N, Kato H, et al. New plasmid-mediated fluoroquinolone efflux pump, QepA, found in an Escherichia coli clinical isolate. Antimicrob Agents Chemother. 2007 Sep;51(9):3354-60.

11. Hansen LH, Johannesen E, Burmølle M, Sørensen AH, Sørensen SJ. Plasmid-encoded multidrug efflux pump conferring resistance to olaquindox in Escherichia coli. Antimicrob Agents Chemother. 2004 Sep;48(9):3332-7.

12. European Committee on Antimicrobial Susceptibility Testing. Antimicrobial susceptibility testing. EUCAST disk diffusion method. Version 2.1. EUCAST; 2012.

13. European Committee on Antimicrobial Susceptibility Testing. Breakpoint tables for interpretation of MICs and zone diameters. Version 3.0 [Internet]. EUCAST; 2013 [cited 2014 Feb 26]. Available from: http://www. eucast.org/fileadmin/src/media/PDFs/EUCAST_files/Disk_test_documents/EUCAST_Breakpoint_table_v_3.0.pdf.

14. Jacoby GA, Chow N, Waites KB. Prevalence of plasmid-mediated quinolone resistance. Antimicrob Agents Chemother. 2003 Feb;47(2):559-62.

15. Ecoli. Bacterial DNA Extraction Kit [Internet]. Bratislava: Ecoli [cited 2014 Feb 26]. Available from: http://www.ecoli.sk/files/documents/btk/ bacterial dna extraction kit \%28column\%29.pdf.

16. Antimicrobial resistance interactive database (EARS-Net) [Internet]. Stockholm: European Centre for Disease Prevention and Control; c20052014 [cited 2014 Feb 26]. Available from: http://www.ecdc.europa.eu/ en/healthtopics/antimicrobial_resistance/database/Pages/database.aspx.

17. Adriaenssens N, Coenen S, Versporten A, Muller A, Minalu G, Faes C, et al.; ESAC Project Group. European Surveillance of Antimicrobial Consumption (ESAC): outpatient quinolone use in Europe (1997-2009). J Antimicrob Chemother. 2011 Dec;66 Suppl 6:vi47-56.

18. Kim ES, Jeong JY, Choi SH, Lee SO, Kim SH, Kim MN, et al. Plasmidmediated fluoroquinolone efflux pump gene, qepA, in Escherichia coli clinical isolates in Korea. Diagn Microbiol Infect Dis. 2009 Nov;65(3):335-8.

19. Piekarska K, Rzeczkowska M, Zacharczuk K, Chróst A, Januszkiewicz A, Bareja E, et al. Prevalence of qnr genes in clinical Enterobacteriaceae non-susceptible to fluoroquinolone in Poland. Med Dosw Mikrobiol. 2012;64(3):211-9. (In Polish.)

20. Kocsis B, Mazzariol A, Kocsis E, Koncan R, Fontana R, Cornaglia G. Prevalence of plasmid-mediated quinolone resistance determinants in Enterobacteriaceae strains isolated in North-East Italy. J Chemother. 2013 Feb;25(1):36-40

21. Sahm DF, Critchley IA, Kelly LJ, Karlowsky JA, Mayfield DC, Thornsberry $\mathrm{C}$, et al. Evaluation of current activities of fluoroquinolones against gram-negative bacilli using centralized in vitro testing and electronic surveillance. Antimicrob Agents Chemother. 2001 Jan;45(1):267-74.

22. Briales A, Rodríguez-Martínez JM, Velasco C, de Alba PD, RodríguezBaño J, Martínez-Martínez L, et al. Prevalence of plasmid-mediated quinolone resistance determinants qnr and aac(6')-Ib-cr in Escherichia coli and Klebsiella pneumoniae producing extended-spectrum $\beta$-lactamases in Spain. Int J Antimicrob Agents. 2012 May;39(5):431-4.

23. Marchese A, Coppo E, Barbieri R, Zoppi S, Pruzzo C, Rossi F, et al. Characterization of fluoroquinolone-resistant Escherichia coli causing septicemic colibacillosis in calves in Italy: emergence of a multiresistant O78 clonal group. Microb Drug Resist. 2012 Feb;18(1):94-9.

Received February 28, 2013 Accepted in revised form February 20, 2014 